\title{
Pulling for the team: Competition between political partisans
}

\author{
Lingbo Huang \\ Economics Experimental Lab, Nanjing Audit University, Nanjing 211815, China, \\ lingbo.huang@outlook.com \\ Peter DeScioli \\ Department of Political Science, Stony Brook University, NY 11794-4392, United States, \\ pdescioli@gmail.com \\ Zahra Murad \\ Department of Economics and Finance, University of Portsmouth, PO1 2UP, United \\ Kingdom,zahra.murad@port.ac.uk
}

\begin{abstract}
To compete for power and resources, people form groups including political parties, special interest groups, and international coalitions. We use economic experiments to investigate how people balance the desire for their group's victory versus their own expenditure of effort. We design an economic tug of war in which the side that exerts greater costly effort wins a prize. In Experiment 1, participants compete individually or in teams, which were assigned arbitrarily. In Experiment 2, participants compete individually or in teams based on political partisanship, Democrats against Republicans. In both experiments, participants shirked by exerting $20 \%$ less effort in teams than in individual competition. Moreover, we did not find an effect of partisan framing: Participants exerted no more effort on political teams than arbitrary teams, contrary to theories asserting the automatic potency of partisanship. We discuss why it is difficult for groups, including political partisans, to mobilize in competition.
\end{abstract}

Keywords: group competition, political partisanship, contest games, shirking, free-riding 


\section{Introduction}

In every arena of politics, people form teams to compete for power and resources.

Citizens and legislators form political parties to vie for control of the government, special interests form lobbies to influence policy, and nations form coalitions to defend their borders. Like other teams, American political parties show both unity and discord within them (Groenendyk, 2013). Many voters and legislators pull together to follow their party's stance on issues, leading to polarization between parties (Iyengar \& Westwood, 2015). At the same time, however, political parties can unravel and splinter, and they must constantly struggle to increase voter turnout (Green \& Gerber, 2015), solicit campaign donations (O’Donnell, 2016), and suppress infighting among copartisan legislators (Bendix \& Mackay, 2017).

Here we use economic experiments to study this fundamental issue for political parties - the tension between the individual and the team. In an experimental microcosm, we stage competitions between individuals, teams, and political partisans to study the psychological forces that hold parties together and pull them apart. We consider two kinds of theories about group competition from the social sciences: One kind emphasizes people's motives to help their group, while the other emphasizes people's motives to shirk in groups.

The first category includes research finding that people have strong motives to advance their ingroup ahead of rival outgroups. These motives may be enhanced by factors such as social identity (Tajfel \& Turner, 1979), social facilitation (Zajonc, 1965), interdependence (Wildschut, Pinter, Vevea, Insko, \& Schopler, 2003), and generalized reciprocity (Yamagishi, Jin, \& Kiyonari, 1999). Particularly, social identity theory holds that people have automatic and powerful ingroup motives, even for minimal groups formed arbitrarily. Moreover, researchers argue that ingroup motives are amplified by group categorization, a clear outgroup, interdependent payoffs, and shared fate (reviewed in Balliet, $\mathrm{Wu}, \& \mathrm{De}$ Dreu, 2014). Importantly, these key factors all apply to team competition, so 
according to social identity theory, people's ingroup motives should intensify when groups compete, showing a kind of team spirit. Moreover, research on political partisanship argues that partisan attachments intensify favoritism toward insiders and hostility toward outsiders (Huddy, Mason, \& Aarøe, 2015; Iyengar, Sood, \& Lelkes, 2012; Iyengar \& Westwood, 2015). Altogether, these ideas point to ingroup identity as a potent force that unifies copartisans for political competition.

Further, a large literature argues that Americans have become increasingly polarized and that partisan hostility extends beyond politics to personal relationships, referred to as affective polarization (Iyengar et al., 2012; Mason, 2015). For instance, participants discriminated against the opposing party in decisions about marriage (Iyengar, et al., 2012; but see Klar, Krupnikov, \& Ryan, 2018), online dating (Huber \& Malhotra, 2017), and economic negotiations (McConnell, Margalit, Malhotra, \& Levendusky, 2018). Research on affective polarization argues that partisan hostility is rooted in social identity, partisan attachment, and political tribalism (Iyengar et al., 2012; Mason, 2015). Hence, affective polarization predicts that Americans will compete more fiercely against people from the opposing party, including beyond politics in spheres such as relationships, business, or sports.

The second category of theories oppositely emphasizes that people tend to shirk in groups. Research on the diffusion of responsibility (Darley \& Latane, 1968; Thomas, De Freitas, DeScioli, \& Pinker, 2016), social loafing (Karau \& Williams, 1993), and free-riding (Fischbacher \& Gächter, 2010) finds persistent shirking in groups. For instance, people are less likely to help others when they are among other bystanders compared to alone (Latane \& Nida, 1981), and in social dilemmas, they are less likely to cooperate in groups compared to when paired with a single partner (Marwell \& Schmitt, 1972). For political partisanship, specifically, some researchers question the power of partisan motives, arguing that many citizens instead feel ambivalent or dislike politics in general, which can decrease their 
political participation and support for the party they prefer (Abramowitz \& Webster, 2016; Klar et al., 2018; Lavine, Johnston, \& Steenbergen, 2013). Overall, these ideas point to the motive to shirk as a force that pulls copartisans apart.

\section{Evolutionary psychology, coalitions, and partisanship}

In an evolutionary timescale, political parties are a recent invention, but the human mind recognizes a political party as a coalition — a group of individuals who work together to compete against rival factions for power and resources (Petersen, 2015; Weeden \& Kurzban, 2014).

Humans have been forming coalitions for hundreds of thousands of years since the origin of the species, and for millions of years before, among our gregarious ancestors such as Homo erectus (Hatala et al., 2016). The human mind is adapted to coalitions like camels are adapted to deserts and gibbons are adapted to trees. Indeed, the foremost theory for why humans evolved a massive brain is that they needed more cognitive power to compete in a complex world of shifting alliances (Byrne \& Whiten, 1998; Dunbar, 2003; Humphrey, 1976).

Coalitions pose difficult problems of computation and strategy, which become clear when we compare across different animal species. Among mammals, out of roughly six thousand species, most are solitary $(\sim 70 \%)$ or pair with a single mate $(\sim 10 \%)$, whereas only $\sim 20 \%$ live in social groups (Lukas \& Clutton-Brock, 2013). Social groups are uncommon because they require special cognition for managing constant interactions with others. Even among the social mammals, most species do not form coalitions. A coalition is more than a simple group such as a flock of sheep, a herd of zebras, or a colony of bats. A coalition refers to a subset of individuals who support each other in conflicts against rival coalitions, especially when these opponents also belong to the same larger group. Thus, a species with coalitions lives in groups and also divides into rival factions within each group. Species that 
form coalitions include dolphins, hyenas, chimpanzees, baboons, and many other primates, and these species evolved cognitive abilities for recruiting allies, coordinating actions, and assessing the strengths of their own and others' coalitions (Cheney \& Seyfarth, 2007; Connor, 2007; de Waal, 2016; Harcourt \& de Waal, 1992; Holekamp, Sakai, \& Lundrigan, 2007).

Humans evolved still more elaborate coalitions (Boehm, 2012; Boyer, 2018; DeScioli \& Kurzban, 2009, 2013; Flinn, Geary, \& Ward, 2005; Macfarlan, Walker, Flinn, \& Chagnon, 2014; Pietraszewski, Cosmides, \& Tooby, 2014; Pratto, Sidanius, \& Levin, 2006; Tooby \& Cosmides, 2010). We form coalitions nested within coalitions, and our loyalties can suddenly shift. Our minds keep track of everyone's allies and enemies in an intricate network of loyalties. Humans marshal coalitions to reinforce dominance hierarchies, but more commonly to oppose hierarchies by ganging up against those who assert power. People can rapidly assemble new coalitions to pursue immediate goals, in addition to forging lasting alliances that span decades. Humans also mobilize coalitions to control the laws that govern society, beginning with moral taboos expressed in language. Altogether, our coalitional mind is more like a Machiavellian playbook of strategies than a simple reflex pitting us against them.

The evolutionary facts about coalitions challenge popular theories of group behavior from the social sciences. Neither coalitions nor political partisanship can be reduced to general psychological processes, including categorization, identity, attachment, reward, affect, or heuristics. While these processes inevitably contribute, they are not sufficient to explain how humans, chimpanzees, or dolphins create coalitions. For instance, the pigeons and rats from classical behaviorism are unable to form coalitions, despite learning from reward and punishment. Thousands of mammal species have attachments (typically mothers and offspring), social categories, and heuristics, but very few create coalitions. 
People's support for their ingroup cannot be explained as an automatic urge, which could not survive evolutionary competition. Even a mother's support for her offspring, the closest relationship, is not automatic in the sense of indiscriminate, but is regulated by psychological mechanisms that weigh fitness costs and benefits (Trivers, 1974). Neither can we really understand shirking in groups by the loose metaphor that responsibility diffuses (Thomas, De Freitas, DeScioli, \& Pinker, 2016). Ultimately, theories of group behavior must contend with the basic fact that humans evolved as coalition specialists.

Likewise, theories of partisanship should recognize that people understand political parties as coalitions. A coalition is not a generic stimulus or attitude object like any other. Coalitions are special objects to the human mind just as flowers are special objects to the honeybee mind. People analyze political parties with the same specialized cognition that they use to strategize and choose sides within the small communities of their personal lives (Petersen, 2015). Thus, the psychology of partisanship begins with the psychology of coalitions.

Coalitional psychology underscores the tension between the individual and the team. Individuals need to muster team spirit to pose a united front against rival coalitions. But individuals can also gain by shirking, conserving their own costs at the expense of the team, provided that this does not reduce the team's chance of success by too much. Thus, people's minds should be alert to both opportunities: team spirit and shirking. The same reasoning applies to political partisanship: People consider the costs, benefits, and others' choices, to decide how much effort to contribute to their political coalition. Thus, the coalition hypothesis predicts that people's partisan motives are not indiscriminate, but are attuned to the costs, opportunities to shirk, and the risk of shirking by other teammates.

\section{Studying group competition: The tug of war game}


We use economic games to study group competition in light of these theories. We stage competitions between individuals, teams, and partisans with real money at stake. We draw on contest games (Dechenaux, Kovenock, \& Sheremeta, 2015), which have been used to model political phenomena including elections, lobbying, and war (e.g., Chaudoin \& Woon, 2018). In a contest game, two opponents decide how much costly effort to expend to compete for a prize. Here we study contests between teams, since competition between political parties is between teams rather than individuals, and we also extend previous work by adding partisanship.

We examine how people muster effort in team competition compared to individual competition. We describe the contest to participants as a tug of war to provide a concrete, familiar theme. A tug of war is analogous to political competition where citizens expend effort to mobilize (pulling the rope) against opponents to influence policy (the prize). In the experiment, each player starts with the same budget of cash and decides how much to spend to pull the (imaginary) rope and how much to keep for themselves. The team that spends more money pulls harder and wins the prize (ties are decided by chance), which is paid in cash to each player on the winning team. In different conditions, participants compete as individuals or in teams. Critically, we hold constant the player's budget (50 cents) and the prize (50 cents per player) so that we can compare participants' effort in teams to individual competition.

Theories about social identity and team spirit predict that participants will come together as a unified team, rather than fracturing as disjointed individuals. According to social identity theory (Tajfel \& Turner, 1979), participants will identify with the team, causing them to pursue the team's payoffs as their own while expecting their teammates to do the same, generating a similar degree of effort as in individual competition when only their own payoff is at stake. Moreover, participants might show even greater effort when teams are 
political, recruiting the motives of affective polarization. On the other hand, theories about shirking predict that participants will show less effort in teams than in individual competition.

In Experiment 1, we examine participants' effort in neutral teams in which players are grouped arbitrarily. If team spirit is readily evoked even in minimal groups, then we will see enhanced effort in arbitrary teams, compared to the baseline of individual competition. If so, this would suggest that basic ingroup motives can spur the kinds of collective effort seen in political parties. In Experiment 2, we examine political teams in which American participants compete in teams based on their political party, Democrats against Republicans. By posing the game as a competition between political partisans, we examine whether participants in teams are more competitive and unified under the influence of partisanship.

\section{Background on Contest Games}

As a secondary point, we can also compare participants' choices to models of contests from game theory (Konrad, 2009; Vojnović, 2016). By assuming self-interest, game theory aligns with theories of shirking, while making specific predictions about how much participants will shirk in these experimental contests.

In the experiments, we compare 1-on-1 competition with two forms of team competition, 3-on-3 and best-of-3. In these contests, the side that invests more total effort, , wins the prize, per player, while the losing side gets nothing. In the best-of-3, the three members of each team compete in three pairwise matches against the members of the opposing team, and the team that wins the most matches wins the prize. We included the best-of-3 as an intermediate form in which players are still on teams but compete individually in matches.

In all cases, a player or team can earn the most by spending slightly more than the opponent, taking the prize at the minimum cost required to win (or by spending nothing if the opponent spends the full value of the prize). But players choose simultaneously so they do 
not know and can only guess each other's efforts. Importantly, there is no pure-strategy equilibrium because for any fixed effort, the opponent's best response is to spend slightly more, so the efforts escalate until one player reaches the prize value; then, the opponent drops their effort to zero, the first player decreases their effort to slightly more than zero, and this process cycles indefinitely (analogous to the cycling of strategies in rock-paper-scissors).

These contests have only mixed strategy equilibria. In the 1 -on-1 contest, the mixedstrategy equilibrium is for each player to choose, in which they randomly choose an effort between 0 and $v$ (Hillman \& Riley, 1989). Hence, this model predicts an overall average effort of $v / 2$ and a uniform distribution of effort.

For the 3-on-3 contest, if the team acted as a unified whole, then it would be equivalent to a 1-on-1 contest with the teams as players so the average effort would again be $v / 2$. However, if players maximize their own payoff, as typically assumed, then there is a continuum of (mostly asymmetric) equilibria in which the team's total effort is (Topolyan, 2014). Therefore, the average effort for the players in each team is . This is $67 \%$ less effort than the 1-on-1 contest for the same payoff per player, meaning players are expected to shirk in teams compared to individual competition.

Finally, in the best-of- 3 contest, each player has a $50 \%$ chance that their own match will determine the winner. This assumes that players reason that their teammates each have a $50 \%$ chance of winning, so there is a $50 \%$ chance that one teammate wins and one loses, which is when the player's own match is decisive. This means winning one's own match is worth $/ 2$ in expectation. Otherwise, each match is equivalent to a 1-on-1 competition, except the prize is discounted to . Therefore, each player's equilibrium effort is, and the expected effort is (Fu, Lu, \& Pan, 2015), which again is less than in individual competition.

Table 1 summarizes the game theory analyses for the three contests. Overall, game theory predicts that players will exert less effort in teams than individual competition, 
consistent with theories of shirking. In the team contests, the specific equilibria represent full shirking for each contest, analogous to contributing 0 in the (one-shot) public goods game.

Table 1. Mixed strategy equilibria for individual and team contests

Contest Equilibrium effort Average effort

1-on-1

3-on-3

Best-of-3

Note: represents the prize per player. In the experiments, we hold constant $v=50$ per player across the different contests.

Previous experiments on group contests have studied different group sizes, coordination mechanisms, and other variations (Sheremeta, 2018). Much of this research focused on the Tullock contest in which effort increases the probability of winning. We use the deterministic contest because we expect it is easier for participants to understand. Few previous studies directly compare individual and team contests. One study found that both individuals and teams (of four) tend to overbid in Tullock contests relative to game theory predictions, and participants exerted less effort in teams than as individuals (Abbink, Brandts, Herrmann, \& Orzen, 2010). We build on previous work by comparing individuals versus teams in deterministic contests, and by examining a contest between political partisans.

\section{Experiment 1}

We recruited $n=312$ participants (age: $M=36.1, S D=11.8 ; 41.3 \%$ female) on Mturk (Berinsky, Huber, \& Lenz, 2012). Participants earned 50 cents for completing the task, and they could earn additional money in the game (up to \$1). 
We randomly assigned participants to one of three between-subject conditions: 1-on1, 3-on-3, or best-of-3 competition. In all conditions, each participant spends up to 50 cents to compete for a prize worth $=50$ cents per player, meaning each winning player earns 50 cents in both the individual and team competitions. Thus, we hold constant participants' budget and the prize, while varying whether they compete as individuals or in teams. With the prize held constant, we can examine participants' effort in teams compared to when they compete individually with the same reward on the line. Participants keep any money they do not spend. The winner is the side that expends more effort, or the team that wins 2 out of 3 matches in the best-of-3 contest (breaking ties by chance).

We described the game as a tug of war to make the competition vivid and easy to understand (Figure 1; see the instructions in the Appendix). Players pull the rope to compete for the prize worth 50 points per player (each point is worth 1 cent). Each player starts with 50 points that they can spend to pull the rope. They click the "pull" button to spend more points and pull harder. If they change their mind, they can click the "ease up" button to move points back to their personal account. After the study, we matched each participant with other participants to reconcile their choices and determine the winners. Each participant earned a bonus of 1 cent per point for the points they kept plus any points they won.

A. 1-on-1 contest

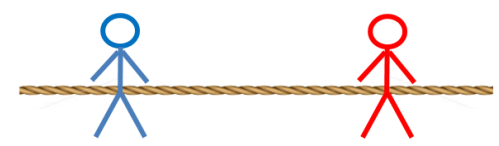

B. 3-on-3 contest

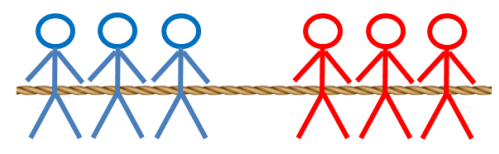

C. best-of-3 contest
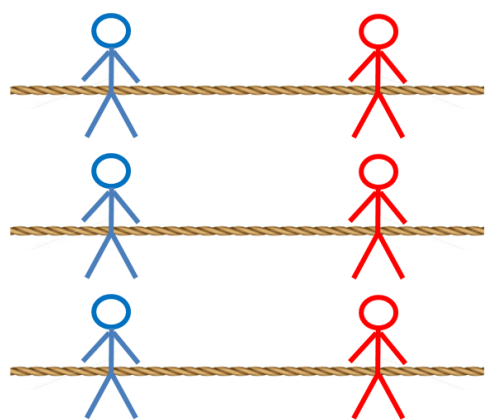

Figure 1. Illustrations of each contest from the experiment's instructions. 
Theories about team spirit predict that participants will expend the same or greater effort in teams (both 3-on-3 and best-of-3) compared to individual competition. To the extent that participants identify with their team, they will act as a unified whole as if they were a single player, or even increase their effort as in classic research on social facilitation. In contrast, theories about shirking predict that participants will expend less effort in teams compared to individual competition. Similarly, game theory (also based on self-interest) predicts less effort in teams than individual competition (Table 1).

Figure 2 (panel A) shows the results. Participants exerted about 20\% less effort in 3on-3 competition than 1-on-1 competition, $t(206)=2.11, p=.036, d=0.29$. This difference indicates that participants shirked in the team competition relative to the efforts they made in the individual competition. Similarly, participants exerted less effort in best-of-3 competition than 1-on-1 competition, $t(203)=3.33, p=.001, d=0.47$. We observed no significant difference in effort between the 3 -on-3 and best-of-3 competitions, $t(209)=1.07, p=.29, d=$ 0.15 , indicating that participants' effort did not depend on the particular form of team competition.

A. Experiment 1, Tug of War

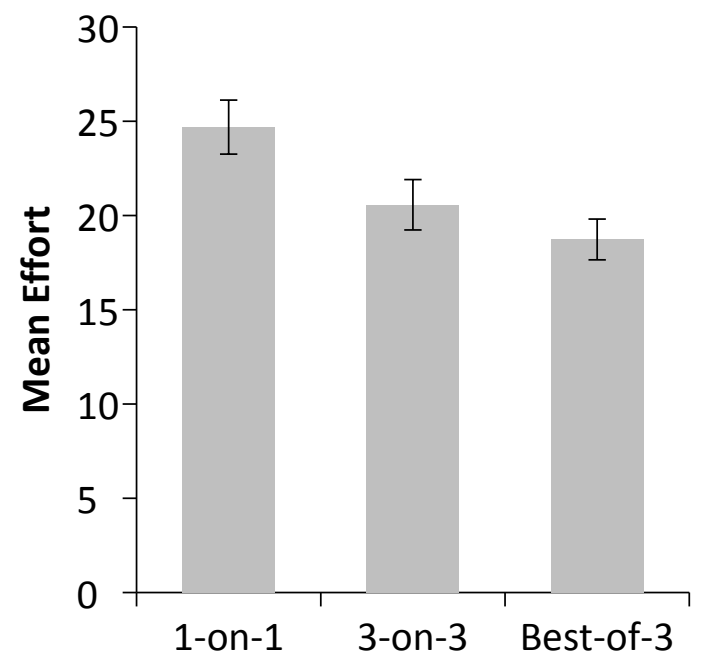

B. Experiment 2, Political Tug of War

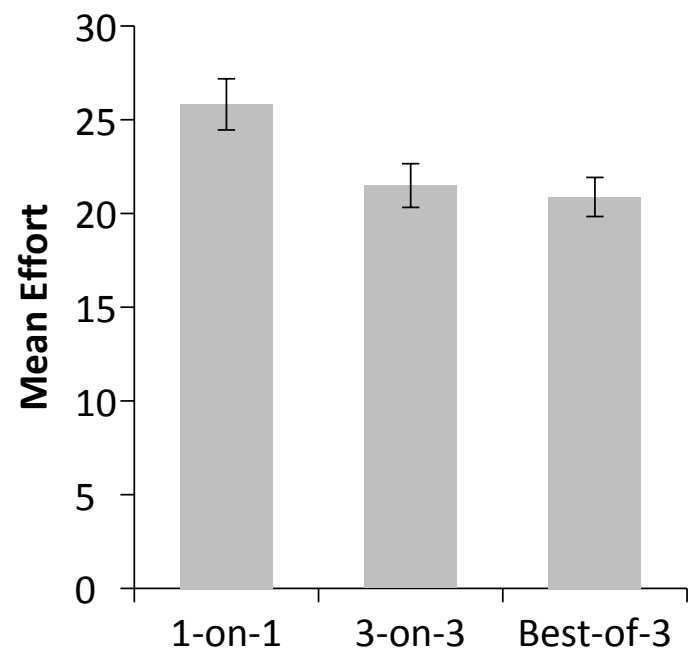


Figure 2. Mean (SE) effort in cents for the tug of war in Experiment 1 (panel A) and the political tug of war in Experiment 2 (panel B). Players could spend up to a maximum of 50 cents. For reference, team spirit predicts the same or more effort in teams compared to 1-on-1 competition, shirking predicts less effort on teams, and shirking according to the mixed strategy equilibria predicts average efforts of 25 in 1-on-1, 8.33 in 3-on-3, and 12.5 in bestof-3 competition.

We also looked more closely at the distributions of effort. Participants were more likely to exert low effort in teams than individual competition, whereas high effort was more frequent in individual competition than teams (Figure S1, Appendix). The distributions of effort were not consistent with the mixed strategy equilibria (see Appendix).

Overall, participants shirked on teams by expending roughly $20 \%$ less effort in team competition than individual competition. This observation supports theories about shirking in groups such as diffusion of responsibility and free-riding, whereas it challenges theories about team spirit such as social identity theory and generalized reciprocity. Even so, participants still contributed substantial effort to their team which likely reflects some team spirit. For comparison, people typically contribute $50 \%$ less than full cooperation in the (oneshot) public goods game (Ledyard, 1995). So, participants arguably shirked less than in other group games without competition, suggesting a mixture of shirking and team spirit.

\section{Experiment 2}

We next ask whether forming teams based on political partisanship can boost team spirit, as predicted by theories about partisan attachment and affective polarization. We used the same tug of war game except with a political framing (see full instructions in the Appendix). Participants first answered which political party they most support (Democrat, Republican, Independent/Other). Participants' partisanship determined their opponents in the game. For example, a Democrat in the 1-on-1 competition read: 
“You said you are a Democrat. You will play against another MTurk

participant who is a Republican and has completed this same HIT."

Throughout the instructions, we refer to the "political tug of war" and say they will compete against opponents from the opposing party. If participants chose Independent/Other $(n=109)$, then they decided whether to compete on the Republican side, the Democrat side, or stay out of the competition and earn a flat payment with no bonus $(n=23)$.

We recruited participants on Mturk and excluded from analysis those who chose to stay out of the political competition, yielding a final sample of $n=412$ (age: $M=34.9, S D=$ $10.3 ; 44.4 \%$ female). Participants earned 50 cents for completing the task and could earn bonus money from the game.

Participants competed in the 1-on-1, 3-on-3, or best-of-3 competition. ${ }^{1}$ Additionally, we varied the partisan framing in three levels of increasing intensity: the partisan condition, described above; the added quote condition, which additionally presented a quote from the party's presidential candidate; and the added prompt condition, in which participants read the quote and wrote about whether it was important to support their party. Moreover, these experimental sessions were conducted the week before the 2016 U.S. Presidential Election, which is expected to further intensify partisan motives (Iyengar et al., 2012).

In the added quote condition, before reading the rules of the game, participants who were Democrats read:

\section{Democrats versus Republicans}

Many Americans believe that the 2016 Presidential Election is a critical crossroads for the nation. The Democratic and Republican candidates have asked for Americans' support.

\footnotetext{
${ }^{1}$ We expected more Democrats than Republicans on Mturk. To accommodate, we sometimes matched a Republican with more than one Democrat, and determined the Republican's bonus based on one of the opponents determined randomly.
} 
The Democratic candidate Hillary Clinton said, "I'm reaching out to all Americans...because we need everybody to help make our country what it should be, to grow the economy, to make it fairer, to make it work for everyone."

In this study, you can support your political party in a political tug of war between participants on the Democratic side and participants on the Republican side.

For Republicans, the second paragraph was instead:

The Republican candidate Donald Trump said, "This election is about every man, woman and child in our country who deserves to live in safety, prosperity and peace...Join me in taking back our country, and creating a bright and glorious new dawn for our people."

In the added prompt condition, participants read the same quotes and additionally answered:

What do you think? Is it important for citizens to make an effort to vote and stand up for their political party and beliefs? Please tell us your thoughts in 3 or 4 sentences.

With quotes about a heated election the same week as our experiment, and by asking participants to write about participation, we aimed to further intensify political identities which is expected to boost partisan motives. After the game participants answered whether they were weak, moderate, or strong Democrats or Republicans. All other measures and procedures were the same as Experiment 1.

Participants' effort did not differ across partisanship, added quote, and added prompt conditions so we combine them (see Table S2 and S3, Appendix for additional analyses broken down by partisan framing). We found no significant differences in effort between Democrats and Republicans; no differences between participants who initially chose 
Independent/Other and those who immediately selected a party; and no differences by partisanship strength (see Table S4, Appendix).

Figure 2 (panel B) shows the main results. Participants exerted about $20 \%$ less effort in 3-on-3 competition than 1-on-1 competition, $t(271)=2.41, p=.017, d=0.29$. Participants also exerted less effort in best-of-3 competition than 1-on-1 competition, $t(276)=2.88, p=$ $.004, d=0.35$. These results show that participants shirked in teams relative to individual competition, even with intense partisan cues. Last, we observed no significant difference in effort between the 3-on-3 and best-of-3 competitions, $t(271)=0.39, p=.70, d=0.05$, which again suggests that effort did not depend on the form of team competition. The distributions of effort showed the same pattern (see Figure S2, Appendix).

Finally, we test whether the political framing promoted greater effort compared to the neutral game in Experiment 1. In all cases, we find no significant difference between political and neutral versions: 1 -on- 1 competition, $t(238)=0.56, p=.58, d=0.073,95 \%$ CI $[-2.8$, 5.1]; 3-on-3 competition, $t(239)=0.52, p=.61, d=0.067,95 \%$ CI $[-2.6,4.4]$; and best-of-3 competition, $t(241)=1.41, p=.16, d=0.18,95 \%$ CI $[-0.86,5.15]$ (see Table S5, Appendix for a complementary regression analysis). But we caution that null effects are difficult to interpret, and we included (above) the 95\% confidence intervals to help assess the range of values consistent with the results. The intervals ranged from contributing roughly 2 cents less up to 5 cents more in each political game compared to the neutral version.

Overall, participants shirked on political teams compared to individual competition. Moreover, participants' effort in political teams (Experiment 2) did not differ from neutral teams (Experiment 1), showing that partisanship did little to increase participants' competitive effort. This experiment used intense partisan cues at a time when U.S. political competition was at an extreme peak just before the 2016 Presidential Election. However, participants still tended to shirk and contributed no more effort than in a neutral competition. 
These results suggest that to boost costly effort in competition, more is needed than framing, political identity, and a salient political conflict. Moreover, this observation suggests that it can be difficult to amplify effort even during a highly contested election. In short, the political frames in the present experiment, including inspirational quotes from presidential candidates and a writing prompt about political participation, were not sufficient to mobilize participants to increase costly effort for their political team.

\section{General Discussion}

Overall, we found that participants exerted less effort in team competition than in individual competition. Essentially, participants pulled for themselves more than they pulled for the team. In Experiment 1, participants competed in neutral teams that were assigned arbitrarily. The player's budget and the reward per player were held constant across 1-on-1, 3-on-3, and best-of-3 competitions. In both forms of team competition, participants exerted roughly $20 \%$ less effort than in individual competition. In Experiment 2, participants competed in political teams, Democrats against Republicans. Again, participants contributed $20 \%$ less effort in team competition than individual competition. Finally, participants' effort in political teams (Experiment 2) did not significantly differ from neutral teams (Experiment 1), contrary to the idea that partisanship automatically evokes fierce competition.

These results resonate with previous research on shirking in groups such as studies on diffusion of responsibility (Darley \& Latane, 1968) and free-riding in public goods games (reviewed in Balliet, Mulder, \& Van Lange, 2011). They also support evolutionary theories about coalitions, which hold that people are alert to opportunities to shirk in teams and to the risks of others' shirking. The present experiments extend observations of shirking to team competition with a clear ingroup and outgroup, and to teams of political partisans. 
In contrast, the results challenge theories asserting that ingroup support is automatic, indiscriminate, and powerful. These experimental competitions had multiple features that these theories predict will amplify ingroup motives, including group categorization, a clear outgroup, interdependent payoffs, and shared fate. Participants still exerted less effort in teams than as individuals. Even so, participants arguably shirked less than might be expected. In the (one-shot) public goods game, participants typically contribute $50 \%$ less than full cooperation (Ledyard, 1995), compared to shirking by about $20 \%$ in the present experiments. Thus, participants' efforts in the present competitions may reflect a mixture of moderate team spirit and moderate shirking.

Perhaps clearer, the results challenge the idea that partisan motives are automatic and powerful even outside of politics, as maintained in theories of affective partisanship. In Experiment 2, Democrats competed against Republicans in a tug of war with political framing that included inspirational quotes from presidential candidates, a writing prompt about supporting the party, and timing during the week before the 2016 Presidential Election. Still, participants contributed no more effort in partisan teams than neutral teams. This finding echoes other research questioning the power of partisan motives. For instance, some citizens are ambivalent toward their party (Lavine et al., 2013), some citizens dislike both parties (Klar \& Krupnikov, 2016), and many citizens view partisanship as less important than other identities including nationality, race, gender, and religion (Druckman \& Levendusky, 2019).

These findings may also help understand how the evolutionary psychology of coalitions shapes political partisanship. If partisan framing is not sufficient to unify partisans, researchers can focus on additional factors such as reputation, communication, and leadership as potential sources of the coalitional aggression behind partisan hostility. For instance, reputation might be among the benefits that the coalitional mind weighs against the costs of 
effort to decide whether fighting outsiders is worthwhile. Researchers might find additional clues by looking at the fitness benefits that motivate coalitional aggression in small-scale societies without political parties and in other coalitional animals such as chimpanzees, baboons, and dolphins.

Accordingly, many other factors remain to be tested in future research. Political teams might exert greater effort if participants play repeatedly, interact with real-time feedback, see their teammates face-to-face, or can punish shirking, as in previous experiments on nonpolitical contests (e.g., Abbink et al., 2010; Chaudoin \& Woon, 2018; Mago, Samak, \& Sheremeta, 2016). Related, research in social psychology on social dilemmas between groups (different from contests) found more intergroup defection when teammates discuss their choices and when they decide by consensus (Wildschut et al., 2003). Communication and consensus within the group might similarly intensify partisan hostility in contests. Also, perhaps partisanship would boost effort if the stakes were directly linked to their parties, such as if the prize money would be donated to either the Democratic Party or Republican Party.

The shirking that we see in political teams might point to something that political candidates know all too well. If partisanship, social categorization, and shared fate were enough to inspire effort, then candidates could readily get citizens to vote and donors to fund their campaigns. But a candidate needs much more than partisan motives and an outgroup to win an election, which is why campaigns are so costly. The present experiments offer a reason: People are alert to opportunities to shirk in teams including political parties.

\section{References}

Abbink, K., Brandts, J., Herrmann, B., \& Orzen, H. (2010). Intergroup conflict and intragroup punishment in an experimental contest game. American Economic Review, $100(1), 420-447$. 
Abramowitz, A. I., \& Webster, S. (2016). The rise of negative partisanship and the nationalization of U.S. elections in the 21st century. Electoral Studies, 41, 12-22.

Balliet, D., Mulder, L. B., \& Van Lange, P. A. M. (2011). Reward, punishment, and cooperation: A meta-analysis. Psychological Bulletin, 137(4), 594-615.

Balliet, D., Wu, J., \& De Dreu, C. K. W. (2014). Ingroup favoritism in cooperation: A metaanalysis. Psychological Bulletin, 140(6), 1556-1581.

Bendix, W., \& Mackay, J. (2017). Partisan infighting among House Republicans: Leaders, factions, and networks of interests. Legislative Studies Quarterly, 42(4), 549-577.

Berinsky, A., Huber, G., \& Lenz, G. (2012). Evaluating online labor markets for experimental research: Amazon. com's Mechanical Turk. Political Analysis, 20, $351-368$.

Boehm, C. (2012). Ancestral hierarchy and conflict. Science, 336(6083), 844-847.

Boyer, P. (2018). Minds make societies. New Haven, CT: Yale University Press.

Byrne, R. W., \& Whiten, A. (1998). Machiavellian intelligence: Social expertise and the evolution of intellect in monkeys, apes and humans. Oxford: Clarendon Press.

Chaudoin, S., \& Woon, J. (2018). How hard to fight? Cross-player effects and strategic sophistication in an asymmetric contest experiment. Journal of Politics, 80(2), 585-600.

Cheney, D. L., \& Seyfarth, R. (2007). Baboon metaphysics: The evolution of a social mind. Chicago, IL: University of Chicago Press.

Connor, R. C. (2007). Dolphin social intelligence: Complex alliance relationships in bottlenose dolphins and a consideration of selective environments for extreme brain size evolution in mammals. Philosophical Transactions of the Royal Society B: Biological Sciences, 362(1480), 587-602.

Darley, J. M., \& Latane, B. (1968). Bystander intervention in emergencies: Diffusion of responsibility. Journal of Personality and Social Psychology, 8(4), 377-383. 
de Waal, F. (2016). Are we smart enough to know how smart animals ar. New York, NY:

W.W. Norton \& Company.

Dechenaux, E., Kovenock, D., \& Sheremeta, R. M. (2015). A survey of experimental research on contests, all-pay auctions and tournaments. Experimental Economics, 18(4), 609-669.

DeScioli, P., \& Kurzban, R. (2009). The Alliance hypothesis for human friendship. PLoS ONE, 4(6), e5802.

DeScioli, P., \& Kurzban, R. (2013). A solution to the mysteries of morality. Psychological Bulletin, 139(2), 477-496.

Druckman, J. N., \& Levendusky, M. S. (2019). What do we measure when we measure affective polarization? Public Opinion Quarterly, 83(1), 114-122.

Dunbar, R. I. M. (2003). The social brain: Mind, language, and society in evolutionary perspective. Annual Review of Anthropology, 32(1), 163-181.

Fischbacher, U., \& Gächter, S. (2010). Social preferences, beliefs, and the dynamics of free riding in public goods experiments. American Economic Review, 100(1), 541-556.

Flinn, M. V., Geary, D. C., \& Ward, C. V. (2005). Ecological dominance, social competition, and coalitionary arms races. Evolution and Human Behavior, 26(1), 10-46.

Fu, Q., Lu, J., \& Pan, Y. (2015). Team contests with multiple pairwise battles. American Economic Review, 105(7), 2120-2140.

Green, D. P., \& Gerber, A. S. (2015). Get out the vote: How to increase voter turnout. Washington, D.C.: Brookings Institution Press.

Groenendyk, E. (2013). Competing motives in the partisan mind. New York, NY: Oxford University Press.

Harcourt, A. H., \& de Waal, F. (1992). Coalitions and alliances in humans and other animals. New York, NY: Oxford University Press. 
Hatala, K. G., Roach, N. T., Ostrofsky, K. R., Wunderlich, R. E., Dingwall, H. L., Villmoare, B. A., ... Richmond, B. G. (2016). Footprints reveal direct evidence of group behavior and locomotion in Homo erectus. Scientific Reports, 6(1), 28766.

Hillman, A. L., \& Riley, J. G. (1989). Politically contestable rents and transfers. Economics and Politics, 1(1), 17-39.

Holekamp, K. E., Sakai, S. T., \& Lundrigan, B. L. (2007). Social intelligence in the spotted hyena ( Crocuta crocuta ). Philosophical Transactions of the Royal Society B: Biological Sciences, 362(1480), 523-538.

Huber, G. A., \& Malhotra, N. (2017). Political homophily in social relationships: Evidence from online dating behavior. Journal of Politics, 79(1), 269-283.

Huddy, L., Mason, L., \& Aarøe, L. (2015). Expressive partisanship: Campaign involvement, political emotion, and partisan identity. American Political Science Review, 109(01), $1-17$.

Humphrey, N. K. (1976). The social function of intellect. In P. P. G. Bateson \& R. A. Hinde (Eds.), Growing points in ethology (pp. 303-317). Cambridge, MA: Cambridge University Press.

Iyengar, S., Sood, G., \& Lelkes, Y. (2012). Affect, not ideology: A social identity perspective on polarization. Public Opinion Quarterly, 76(3), 405-431.

Iyengar, S., \& Westwood, S. J. (2015). Fear and loathing across party lines: New evidence on group polarization. American Journal of Political Science, 59(3), 690-707.

Karau, S. J., \& Williams, K. D. (1993). Social loafing: A meta-analytic review and theoretical integration. Journal of Personality and Social Psychology, 65(4), 681-706.

Klar, S., \& Krupnikov, Y. (2016). Independent politics: How American disdain for parties leads to political inaction. New York, NY: Cambridge University Press.

Klar, S., Krupnikov, Y., \& Ryan, J. B. (2018). Affective polarization or partisan disdain? 
Public Opinion Quarterly, 82(2), 379-390.

Konrad, K. A. (2009). Strategy and dynamics in contests. New York, NY: Oxford University Press.

Latane, B., \& Nida, S. (1981). Ten years of research on group size and helping. Psychological Bulletin, 89(2), 308-324.

Lavine, H. G., Johnston, C. D., \& Steenbergen, M. R. (2013). The ambivalent partisan: How critical loyalty promotes democracy. New York, NY: Oxford University Press.

Ledyard, J. O. (1995). Public goods: A survey of experimental research. In The Handbook of Experimental Economics (pp. 111-194). Princeton, NJ: Princeton University Press.

Lukas, D., \& Clutton-Brock, T. H. (2013). The evolution of social monogamy in mammals. Science, 341(6145), 526-530.

Macfarlan, S. J., Walker, R. S., Flinn, M. V., \& Chagnon, N. A. (2014). Lethal coalitionary aggression and long-term alliance formation among Yanomamö men. Proceedings of the National Academy of Sciences, 111(47), 16662-16669.

Mago, S. D., Samak, A. C., \& Sheremeta, R. M. (2016). Facing your opponents. Journal of Conflict Resolution, 60(3), 459-481.

Marwell, G., \& Schmitt, D. R. (1972). Cooperation in a three-person Prisoner's Dilemma. Journal of Personality and Social Psychology, 21(3), 376-383.

Mason, L. (2015). "I disrespectfully agree": The differential effects of partisan sorting on social and issue polarization. American Journal of Political Science, 59(1), 128-145.

McConnell, C., Margalit, Y., Malhotra, N., \& Levendusky, M. (2018). The economic sonsequences of partisanship in a polarized era. American Journal of Political Science, $62(1), 5-18$.

O’Donnell. (2016, April 24). Are members of congress becoming telemarketers? Retrieved from http://www.cbsnews.com/news/60-minutes-are-members-of-congress-becoming- 
telemarketers/

Petersen, M. B. (2015). Evolutionary political psychology. In D. M. Buss (Ed.), The Handbook of Evolutionary Psychology, Second Edition (pp. 1084-1100). Hoboken, NJ: Wiley.

Pietraszewski, D., Cosmides, L., \& Tooby, J. (2014). The content of our cooperation, not the color of our skin: An alliance detection system regulates categorization by coalition and race, but not sex. PLoS ONE, 9(2), e88534.

Pratto, F., Sidanius, J., \& Levin, S. (2006). Social dominance theory and the dynamics of intergroup relations: Taking stock and looking forward. European Review of Social Psychology, 17(1), 271-320.

Sheremeta, R. M. (2018). Behavior in group contests: A review of experimental research. Journal of Economic Surveys, 32(3), 683-704.

Tajfel, H., \& Turner, J. (1979). An integrative theory of intergroup behavior. In S. Worchel \& W. Austin (Eds.), The Social Psychology of Intergroup Relations (pp. 33-47). Monterey, CA: Brooks/Cole.

Thomas, K. A., De Freitas, J., DeScioli, P., \& Pinker, S. (2016). Recursive mentalizing and common knowledge in the bystander effect. Journal of Experimental Psychology: General, 145(5), 621-629.

Tooby, J., \& Cosmides, L. (2010). Groups in mind: The coalitional roots of war and morality. In H. Høgh-Olesen (Ed.), Human morality and sociality: Evolutionary and comparative perspectives (pp. 91-234). New York, NY: Palgrave Macmillan.

Topolyan, I. (2014). Rent-seeking for a public good with additive contributions. Social Choice and Welfare, 42(2), 465-476.

Trivers, R. L. (1974). Parent-offspring conflict. American Zoologist, 14(1), 249-264. Vojnović, M. (2016). Contest theory: incentive mechanisms and ranking methods. New 
York, NY: Cambridge University Press.

Weeden, J., \& Kurzban, R. (2014). The hidden agenda of the political mind. Princeton, NJ: Princeton University Press.

Wildschut, T., Pinter, B., Vevea, J. L., Insko, C. A., \& Schopler, J. (2003). Beyond the group mind: A quantitative review of the interindividual-intergroup discontinuity effect. Psychological Bulletin, 129(5), 698-722.

Yamagishi, T., Jin, N., \& Kiyonari, T. (1999). Bounded generalized reciprocity: Ingroup boasting and ingroup favoritism. Advances in Group Processes, 16, 161-197.

Zajonc, R. B. (1965). Social facilitation. Science, 149(3681), 269-274. 


\section{Appendix}

\section{Additional Results for Experiment 1}

In the main text, we reported the average effort. Here, we examine the distributions of effort, especially to test theoretical predictions about high and low effort. We use five blocks of effort, $0-9,10-19,20-29,30-39,40-50$, to display the effort distribution in each condition (Figure S1). Overall, the three distributions are significantly different, ${ }^{2}(8)=22.20, p=.005$, $=.19$. Specifically, the distribution in 1 -on- 1 competition differs from both 3 -on- $3,{ }^{2}(4)=$ $10.40, p=.034,=.22$, and best-of- $3,{ }^{2}(4)=14.96, p=.005,=.27$; however, the 3 -on-3 distribution does not significantly differ from best-of $-3,{ }^{2}(4)=7.16, p=.13,=.18$. Hence, the pattern is the same as for average effort reported above, with differences between individual and team but not across different rules for team competition.

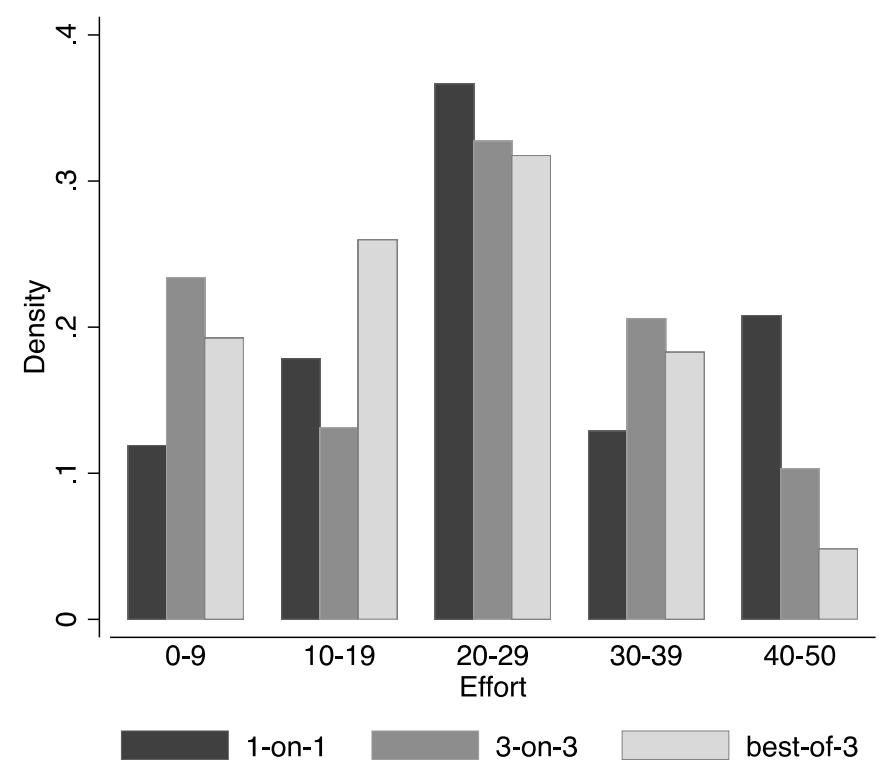

Figure S1. Distribution of Effort in Tug-of-War (Experiment 1)

Furthermore, the distributions allow us to test more specifically the prediction that there will be greater free-riding in teams than in individual competition. We find that participants were more likely to choose low effort (block 0-9) in the 3-on-3 condition than the 
1-on-1 condition, ${ }^{2}(1)=4.68, p=.030,=.15$, supporting this prediction. However, the rates of low effort in best-of-3 did not differ from 1-on-1 competition, ${ }^{2}(1)=2.10, p=.15,=.10$. Last, low effort in best-of-3 did not differ from 3-on-3, ${ }^{2}(1)=0.54, p=.46,=.051$.

Similarly, we looked at how often participants contributed the highest level of effort (block 40-50). Participants were more likely to exert high effort in the 1-on-1 contest compared to the 3 -on- 3 contest, ${ }^{2}(1)=4.41, p=.036,=.15$ and the best-of- 3 contest, ${ }^{2}(1)=$ $11.82, p=.001,=.24$. The rates of high effort did not differ between 3-on-3 and best-of-3 contests, ${ }^{2}(1)=2.25, p=.13,=.10$. Hence, consistent with shirking on teams, participants exerted the highest level of effort more often in individual competition than either form of team competition.

Finally, we test whether the effort distribution conforms to the mixed strategy equilibria, that is, the uniform distribution. In 1-on-1, we reject the uniform distribution, ${ }^{2}(50)$ $=280.24, p<.001$; participants' efforts were concentrated in the middle of the distribution, inconsistent with the mixed strategy equilibrium. In 3-on-3, the distribution of effort is well above the predicted one in which the total team effort is uniformly distributed from 0 to 50 . The best-of- 3 is far off the mark since the predicted distribution is uniform from 0 to 25 and the observed one has many observations beyond 25 . Thus, the distributions of effort are not consistent with the mixed strategy equilibria for any of these contests.

\section{Additional Results for Experiment 2, Political Tug-of-War}

Figure S2 shows the distributions of effort. Overall, the three distributions are significantly different, ${ }^{2}(8)=28.94, p<.001,=.19$. Specifically, the distribution for $1-$ on- 1 competition differs from both 3 -on- $3,{ }^{2}(4)=13.79, p=.008,=.22$, and best-of-3, ${ }^{2}(4)=$ 22.47, $p<.001,=.28$, whereas 3-on-3 and best-of-3 do not differ, ${ }^{2}(4)=1.90, p=.75,=$ .083. These comparisons show the same pattern as average effort, above. 


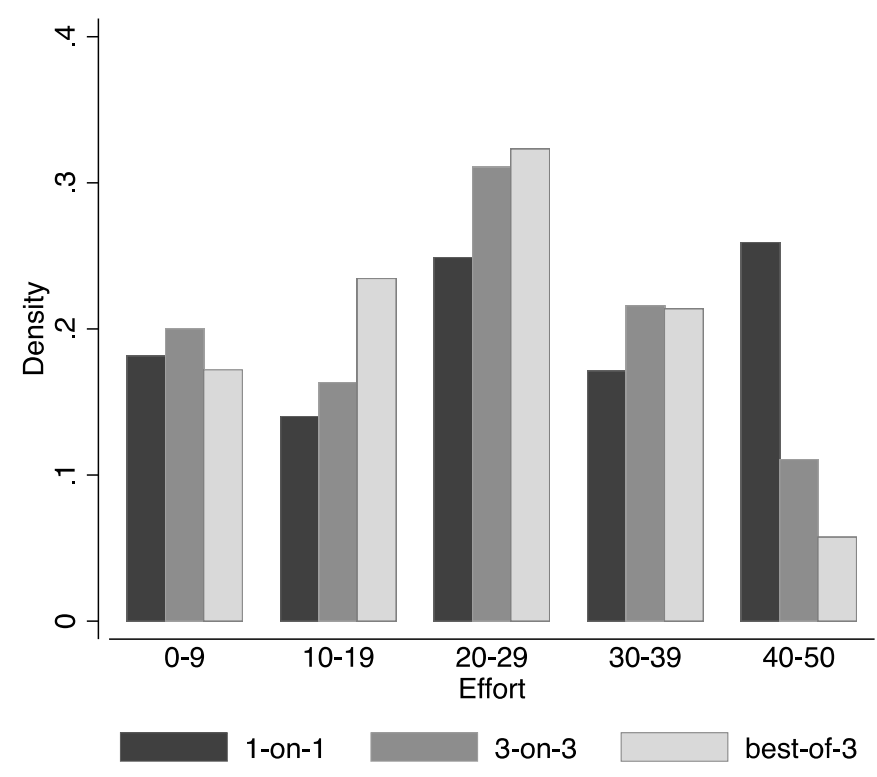

Figure S2. Distribution of Effort in Political Tug-of-War (Experiment 2)

Looking at the lowest effort level, unlike Experiment 1, participants were not more likely to choose low effort in individual competition than either form of team competition (all $p \mathrm{~s}>.75)$. But for the highest effort level, consistent with Experiment 1, participants were more likely to choose high effort (block 40-50) in the 1-on-1 contest than in the 3-on-3 contest, ${ }^{2}(1)=13.05, p<.001,=.22$, and the best-of- 3 contest, ${ }^{2}(1)=20.42, p<.001,=.27$, whereas 3-on-3 and best-of-3 contests did not differ, ${ }^{2}(1)=0.96, p=.33,=.059$.

Finally, we examine whether the distributions of effort conform to the mixed strategy equilibria. In 1-on-1, we reject the uniform distribution, ${ }^{2}(50)=346.42, p<.001$. In 3 -on-3 and best-of-3, the effort distributions are well above the predicted ones. Thus, similar to Experiment 1, the distributions of effort are not consistent with the mixed strategy equilibria for any of these contests.

Table S2 shows descriptive statistics for participants' effort broken down by the intensity of partisanship framing (partisanship, added quote, added prompt) and the participant's political party. Combining across framing conditions, we find no significant difference between Democrats and Republicans in all competitions: 1-on-1 competition, 
$t(137)=1.11, p=.27 ; 3$-on-3 competition, $t(132)=0.60, p=.55 ;$ and best-of- 3 competition, $t(137)=0.99, p=.33$.

We also found no differences in effort between participants who initially selected Independent/Other before choosing a party, and those who immediately selected a party. In 1on-1 competition, effort did not differ between initially independents, $M(S D)=26.12(16.64)$, and partisans, $M(S D)=25.70(15.95), t(137)=0.14, p=.89$. In 3-on-3 competition, effort did not differ between initially independents, $M(S D)=20.42(13.87)$, and partisans, $M(S D)=$ $21.87(13.39), t(132)=0.55, p=.58$. In best-of-3 competition, effort did not differ between initially independents, $M(S D)=20.47(12.74)$, and partisans, $M(S D)=21.01(12.20), t(137)=$ $0.22, p=.83$.

Table S2: Effort in Political Tug-of-War (Experiment 2)

\begin{tabular}{|c|c|c|c|c|c|c|c|c|c|c|c|c|}
\hline \multirow[t]{2}{*}{ Condition } & \multicolumn{3}{|c|}{ Partisanship } & \multicolumn{3}{|c|}{ Added Quote } & \multicolumn{3}{|c|}{ Added Prompt } & \multicolumn{3}{|c|}{ All } \\
\hline & $\mathbf{n}$ & $\begin{array}{c}\text { Mea } \\
\text { n }\end{array}$ & SD & $\mathbf{n}$ & $\begin{array}{c}\text { Mea } \\
\text { n }\end{array}$ & SD & $\mathbf{n}$ & $\begin{array}{c}\text { Mea } \\
\text { n }\end{array}$ & SD & $\mathbf{n}$ & $\begin{array}{c}\text { Mea } \\
\text { n }\end{array}$ & SD \\
\hline \multirow[t]{2}{*}{ 1-on-1 } & 5 & 24.08 & 16.0 & 4 & 28.14 & 16.6 & 4 & 25.15 & 15.4 & 13 & 25.82 & 16.0 \\
\hline & $\mathbf{0}$ & & 8 & 9 & & 4 & $\mathbf{0}$ & & 6 & 9 & & 9 \\
\hline \multirow[t]{2}{*}{ Democrat } & 3 & 25.22 & 16.9 & 3 & 28.28 & 15.4 & 2 & 26.64 & 16.3 & 10 & 26.75 & 16.1 \\
\hline & 7 & & 7 & 9 & & 5 & 5 & & 9 & 1 & & 4 \\
\hline \multirow[t]{2}{*}{ Republican } & 1 & 20.85 & 13.3 & 1 & 27.60 & 21.6 & 1 & 22.67 & 13.9 & 38 & 23.34 & 15.8 \\
\hline & 3 & & 2 & 0 & & 2 & 5 & & 6 & & & 8 \\
\hline \multirow[t]{2}{*}{ 3-on-3 } & 4 & 20.76 & 13.6 & 4 & 22.38 & 14.2 & 3 & 21.30 & 12.5 & 13 & 21.49 & 13.4 \\
\hline & 9 & & 3 & 8 & & 3 & 7 & & 7 & 4 & & 9 \\
\hline \multirow[t]{2}{*}{ Democrat } & 3 & 22.83 & 13.5 & 3 & 23.48 & 13.3 & 2 & 19.00 & 14.2 & 84 & 22.02 & 13.4 \\
\hline & 0 & & 1 & 1 & & 1 & 3 & & 5 & & & 8 \\
\hline \multirow[t]{2}{*}{ Republican } & 1 & 17.47 & 14.6 & 1 & 20.35 & 15.9 & 1 & 25.07 & 8.32 & 50 & 20.58 & 13.5 \\
\hline & 9 & & 0 & 7 & & 9 & 4 & & & & & 8 \\
\hline \multirow[t]{2}{*}{ Best-of-3 } & 4 & 17.37 & 11.3 & 5 & 23.60 & 12.3 & 4 & 21.78 & 12.6 & 13 & 20.88 & 12.2 \\
\hline & 9 & & 6 & $\mathbf{0}$ & & 2 & $\mathbf{0}$ & & 1 & 9 & & 9 \\
\hline \multirow[t]{2}{*}{ Democrat } & 3 & 15.59 & 9.96 & 4 & 22.73 & 11.3 & 2 & 21.93 & 12.2 & 10 & 20.25 & 11.5 \\
\hline & 2 & & & 1 & & 3 & 8 & & 6 & 1 & & 3 \\
\hline \multirow[t]{2}{*}{ Republican } & 1 & 20.71 & 13.3 & 9 & 27.56 & 16.3 & 1 & 21.42 & 12.9 & 38 & 22.55 & 14.1 \\
\hline & 7 & & 0 & & & 3 & 2 & & 6 & & & 5 \\
\hline
\end{tabular}

Table S3 reports a regression analysis for the effect of different intensities of partisan framing on participants' effort in the game (in the three types of contests). Both models (with and without demographics) find no significant effects of the different intensities of partisan 
framing, or interactions with the type of competition. Hence, in the main text for Experiment 2 we combine the data across the political framing conditions.

Table S3: Regression Analysis of Effort by Intensity of Political Framing (Experiment 2)

\begin{tabular}{|c|c|c|c|c|}
\hline & \multicolumn{2}{|l|}{$(1)$} & \multicolumn{2}{|l|}{$(2)$} \\
\hline & $\begin{array}{c}\text { Coefficien } \\
t\end{array}$ & $\mathrm{SE}$ & Coefficient & $\mathrm{SE}$ \\
\hline Quote & 4.06 & $\begin{array}{c}3.2 \\
9\end{array}$ & 4.65 & $\begin{array}{c}3.3 \\
9\end{array}$ \\
\hline Prompt & 1.07 & $\begin{array}{c}3.3 \\
4\end{array}$ & 1.45 & $\begin{array}{c}3.3 \\
6\end{array}$ \\
\hline 3-on-3 & -3.32 & $\begin{array}{c}3.0 \\
0\end{array}$ & -2.01 & $\begin{array}{c}3.0 \\
4\end{array}$ \\
\hline Best-of-3 & $-6.71 *$ & $\begin{array}{c}2.8 \\
0\end{array}$ & $-5.68 *$ & $\begin{array}{c}2.8 \\
8\end{array}$ \\
\hline Quote $\times 3$-on-3 & -2.44 & $\begin{array}{c}4.3 \\
4\end{array}$ & -3.64 & $\begin{array}{c}4.3 \\
6\end{array}$ \\
\hline Quote $\times$ Best-of-3 & 2.17 & $\begin{array}{c}4.0 \\
6\end{array}$ & 0.87 & $\begin{array}{c}4.1 \\
5\end{array}$ \\
\hline Prompt $\times 3-$ on-3 & -0.53 & $\begin{array}{c}4.3 \\
8\end{array}$ & -0.93 & $\begin{array}{c}4.3 \\
9\end{array}$ \\
\hline $\begin{array}{l}\text { Prompt } \times \text { Best-of- } \\
3\end{array}$ & 3.34 & $\begin{array}{c}4.2 \\
1\end{array}$ & 2.28 & $\begin{array}{c}4.4 \\
3\end{array}$ \\
\hline Constant & $24.08 * * *$ & $\begin{array}{c}2.2 \\
8\end{array}$ & $15.80 * * *$ & $\begin{array}{c}4.5 \\
4\end{array}$ \\
\hline $\begin{array}{l}R^{2} \\
N\end{array}$ & $\begin{array}{c}0.043 \\
412\end{array}$ & & $\begin{array}{c}0.074 \\
412\end{array}$ & \\
\hline
\end{tabular}

Note. We use the basic partisan condition and 1-on-1 competition as the reference group. Reported coefficients are from OLS regressions with robust standard errors. Model 1 is without demographics and Model 2 includes demographics (sex, age, race/ethnicity, political party, religion, and income level). For demographics, participants who initially chose independent are coded as independent for their political party (rather than the party they chose for the game).

$* p<.05, * * p<.01, * * * p<.001$

We next look at how a participant's partisanship strength affected their effort in the game. We folded the partisanship strength scale so that weak $=0$, moderate $=1$, and strong $=$ 2 for both Democrats and Republicans. Overall, the average partisan strength for Democrats $(\mathrm{n}=285)$ was $M(S D)=0.86(0.83)$, and for Republicans $(\mathrm{n}=123)$ it was $M(S D)=0.64$ (0.73). Table $\mathrm{S} 4$ reports a regression analysis of effort by partisanship strength, with and without demographic variables. We find no significant effects of a participant's reported partisanship strength on the effort they exerted to compete in the political tug-of-war. 
Table S5 reports a regression analysis that compares effort in the neutral game (Experiment 1) to the political game (Experiment 2), with and without demographic variables. We find no significant effects of neutral versus political framing on effort (combining all three intensity conditions in Experiment 2).

Table S4: Regression Analysis of Effort by a Participant's Partisanship Strength

\begin{tabular}{lcccc}
\hline & \multicolumn{2}{c}{$(1)$} & \multicolumn{2}{c}{$(2)$} \\
\cline { 2 - 5 } & $\begin{array}{c}\text { Coefficien } \\
\mathrm{t}\end{array}$ & $\mathrm{SE}$ & $\begin{array}{c}\text { Coefficien } \\
\mathrm{t}\end{array}$ & $\mathrm{SE}$ \\
\hline $\begin{array}{l}\text { Partisanship } \\
\text { Strength }\end{array}$ & 2.34 & 1.6 & 2.50 & 1.7 \\
3-on-3 & & 5 & & 0 \\
& -2.33 & 2.4 & -1.11 & 2.5 \\
Best-of-3 & -3.69 & 2.3 & -3.12 & 2.4 \\
Strength $\times$ 3-on-3 & -1.96 & 2.1 & -2.69 & 2.2 \\
& & 7 & & 3 \\
Strength $\times$ Best-of-3 & -1.38 & 2.0 & -1.75 & 2.1 \\
& & 9 & & 3 \\
Constant & $23.80 * * *$ & 1.8 & $16.75 * * *$ & 4.2 \\
& & 5 & & 0 \\
$R^{2}$ & 0.030 & & 0.059 & \\
$N$ & 408 & & 408 & \\
\hline
\end{tabular}

Note. Participants' partisanship strength responses were combined across Democrats and Republicans and folded so that weak $=0$, moderate $=1$, and strong $=2$. Reported coefficients are from OLS regressions with robust standard errors. Model 1 is without demographics and Model 2 is with demographics (sex, age, race/ethnicity, political party, religion, and income level). For demographics, participants who initially chose independent are coded as independent for their political party (rather than the party they chose for the game).

${ }^{*} p<.05, * * p<.01, * * * p<.001$

Table S5: Regression Analysis of Effort by Political Framing (Experiments 1 and 2)

\begin{tabular}{lcccccc}
\hline & \multicolumn{4}{c}{$(1)$} & \multicolumn{3}{c}{$(2)$} \\
\cline { 2 - 7 } & Coef & SE & $95 \%$ CI & Coef & SE & $95 \%$ CI \\
\hline Political & 1.23 & 1.98 & {$[-3.00,4.86]$} & 1.15 & 1.98 & {$[-3.03,4.86]$} \\
3-on-3 & $-4.12^{*}$ & 1.96 & {$[-8.11,-0.31]$} & -3.66 & 1.97 & {$[-7.72,0.11]$} \\
Best-of-3 & $-5.96 * * *$ & 1.79 & {$[-9.62,-2.49]$} & $-5.92 * * *$ & 1.81 & {$[-9.67,-2.46]$} \\
Pol $\times 3-$-on-3 & -0.21 & 2.66 & {$[-4.96,5.56]$} & -0.32 & 2.68 & {$[-5.14,5.48]$}
\end{tabular}




\begin{tabular}{lcccccc} 
Pol $\times$ Best-of-3 & -1.02 & 2.48 & {$[-3.73,6.11]$} & 0.93 & 2.13 & {$[-3.86,6.19]$} \\
Constant & $24.69^{* * *}$ & 1.43 & {$[21.92,27.65]$} & $22.52^{* * *}$ & 2.91 & {$[16.96,28.46]$} \\
$R^{2}$ & 0.031 & & & 0.056 & & \\
$N$ & 724 & & & 724 & & \\
\hline
\end{tabular}

Note. Reported coefficients are from OLS regressions with robust standard errors.

Model 1 is without demographics and Model 2 is with demographics.

$* p<.05, * * p<.01, * * * p<.001$ 


\section{Experimental Instructions and Questionnaire}

Note: The instructions differences between treatments are highlighted in blue, but not in actual experiments.

\section{Experiment 1: Neutral frame}

[1-on-1 competition]

\section{Instructions}

In this HIT, you will play a game of tug of war with another Mturk participant. Although the game is fictional, you will earn real money based on the points you score in the game.

Specifically, you will earn 1 cent for each point of your final score.

You will earn 50 cents for completing this HIT, and you can make additional money in the game. Your additional earnings will be paid to you as a Mturk bonus.

\section{Tug of War}

In this game, you play tug of war against an opponent. You pull on one side of a rope and the opponent pulls on the other side. The side that pulls harder wins the competition.

Each player starts with 50 points and decides how many points to spend to pull the rope.

Pulling the rope costs you points because it takes a lot of energy. The more points you spend, the harder you pull.

If you pull harder than your opponent by spending more points, then you win the match. If both sides pull with the same amount of force, then it's a tie and the winner is randomly determined by a coin flip.

The winner receives a prize of 50 points and the loser receives 0 points.

Your final score in the game is the points you have left after the competition plus any points you win as a prize. Your final score determines your Mturk bonus payment, 1 cent per point.

Here is an example. You start with 50 points and then spend 20 points to pull the rope. If you spend more points than the opponent, then you win an additional prize of 50 points. Your final score would be your remaining 30 points plus your prize of 50 points for a total of 80 points.

\section{Summary}

--You compete with another participant in tug of war.

--Each player starts with 50 points and decides how many points to spend to pull the rope.

You keep the remaining points you don't spend.

--The player who pulls harder wins the match. If there is a tie, the winner is randomly determined.

--The winner receives 50 points.

--Your final score is your remaining points plus any points (50 or 0$)$ you win as a prize.

--You earn 1 cent per point, paid as an Mturk bonus.

\section{Comprehension Questions}

Please answer the following comprehension questions. 
1. Suppose you spend 30 points to pull the rope and your opponent spends 20 points, what will be your Mturk bonus? (Answer: d)
a) 20 cents
b) 30 cents
c) 50 cents
d) 70 cents
e) 80 cents

2. Suppose you spend 20 points to pull the rope and your opponent spends 30 points, what will be your Mturk bonus? (Answer: $b$ )
a) 20 cents
b) 30 cents
c) 50 cents
d) 70 cents
e) 80 cents

\section{Make Your Decision}

Now it's time to play tug of war. Click Pull to spend your starting points to pull on the rope. Click Ease Up to change your mind and move points back to Your Points.

Your Points: 50

Points spent on pulling: 0

\section{PULL}

\section{EASE UP}

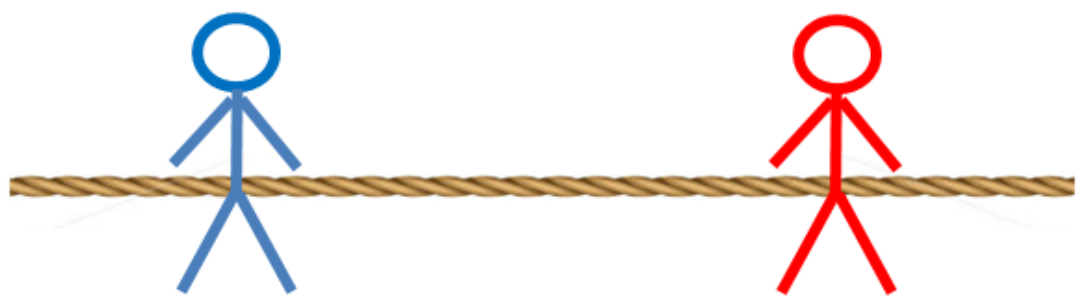

[3-on-3 competition]

\section{Instructions}

In this HIT, you will play a game of tug of war with other Mturk participants. Although the game is fictional, you will earn real money based on the points you score in the game. Specifically, you will earn 1 cent for each point of your final score.

You will earn 50 cents for completing this HIT, and you can make additional money in the game. Your additional earnings will be paid to you as a Mturk bonus.

\section{Tug of War}

In this game, you play tug of war against an opponent. You pull on one side of a rope and the opponent pulls on the other side. The side that pulls harder wins the competition. 
Each player starts with 50 points and decides how many points to spend to pull the rope. Pulling the rope costs you points because it takes a lot of energy. The more points you spend, the harder you pull.

If you pull harder than your opponent by spending more points, then you win the match. If both sides pull with the same amount of force, then it's a tie and the winner is randomly determined by a coin flip.

You will compete in teams of 3 players. You will be assigned to a team with two other participants and your team will compete against another team of 3 participants. The force of the team's pull is the total points that each player spends to pull the rope. The team that pulls harder wins the competition.

The winning team receives a prize of 50 points for each player and the losing team receives 0 points for each player.

Your final score in the game is the points you have left after the competition plus any points you win as a prize. Your final score determines your Mturk bonus payment, 1 cent per point.

Here is an example. You start with 50 points and then spend 20 points to pull the rope. If your team spends more total points than the opposing team, then you win an additional prize of 50 points. Your final score would be your remaining 30 points plus your prize of 50 points for a total of 80 points.

\section{Summary}

--You compete in teams of three in tug of war.

--Each player starts with 50 points and decides how many points to spend to pull the rope.

You keep the remaining points you don't spend.

--The team that pulls harder wins the match. If there is a tie, the winner is randomly

determined.

--The players on the winning team receive a prize of 50 points each.

--Your final score is your remaining points plus any points (50 or 0$)$ you win as a prize.

--You earn 1 cent per point, paid as an Mturk bonus.

\section{Comprehension Questions}

Please answer the following comprehension questions.

1. Suppose all three players on your team spend 30 points each to pull the rope, and all three players on the opposing team spend 20 points each, what will be your Mturk bonus? (Answer: d)
a) 20 cents
b) 30 cents
c) 50 cents
d) 70 cents
e) 80 cents

2. Suppose all three players on your team spend 20 points each to pull the rope, and all three players on the opposing team spend 30 points each, what will be your Mturk bonus? (Answer: b)

a) 20 cents 
b) 30 cents

c) 50 cents

d) 70 cents

e) 80 cents

\section{Make Your Decision}

Now it's time to play tug of war. Click Pull to spend your starting points to pull on the rope. Click Ease Up to change your mind and move points back to Your Points.

Your Points: 50

Points spent on pulling: 0

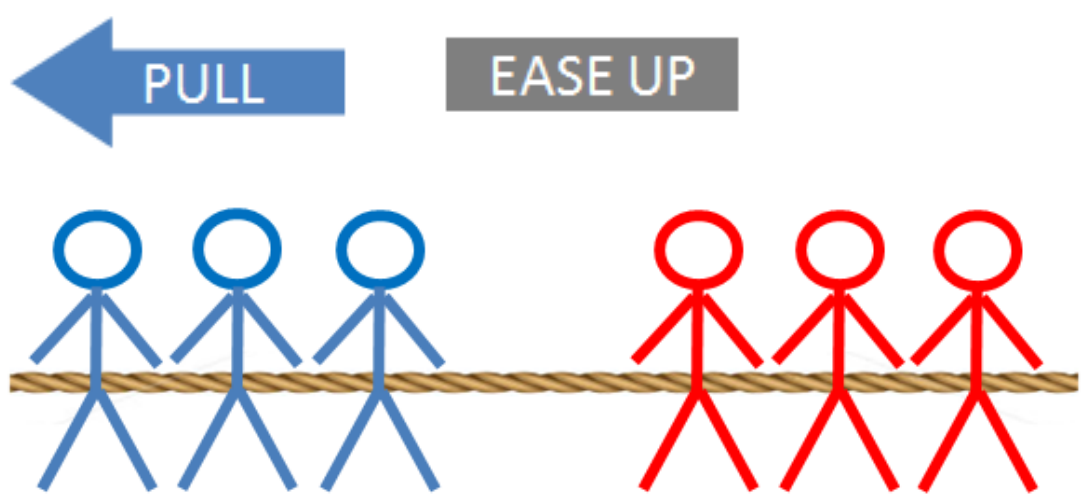

[best-of-3 competition]

\section{Instructions}

In this HIT, you will play a game of tug of war with other Mturk participants. Although the game is fictional, you will earn real money based on the points you score in the game. Specifically, you will earn 1 cent for each point of your final score.

You will earn 50 cents for completing this HIT, and you can make additional money in the game. Your additional earnings will be paid to you as a Mturk bonus.

\section{Tug of War}

In this game, you play tug of war against an opponent. You pull on one side of a rope and the opponent pulls on the other side. The side that pulls harder wins the competition.

Each player starts with 50 points and decides how many points to spend to pull the rope. Pulling the rope costs you points because it takes a lot of energy. The more points you spend, the harder you pull.

If you pull harder than your opponent by spending more points, then you win the match. If both sides pull with the same amount of force, then it's a tie and the winner is randomly determined by a coin flip.

You will compete in teams of 3 players. You will be assigned to a team with two other participants and your team will compete against another team of 3 participants. Then there are three matches in which one player from each team plays tug of war against an opponent from the rival team. The team that wins two out of three matches wins the competition. 
The winning team receives a prize of 50 points for each player and the losing team receives 0 points for each player.

Your final score in the game is the points you have left after the competition plus any points you win as a prize. Your final score determines your Mturk bonus payment, 1 cent per point.

Here is an example. You start with 50 points and then spend 20 points to pull the rope. If your team wins two out of three matches, then you win an additional prize of 50 points. Your final score would be your remaining 30 points plus your prize of 50 points for a total of 80 points.

\section{Summary}

--You compete in teams of three in tug of war. There are three matches between two players. --Each player starts with 50 points and decides how many points to spend to pull the rope. You keep the remaining points you don't spend.

--The player who pulls harder wins the match. If there is a tie, the winner is randomly determined.

--The team that wins two out of three matches wins the competition.

--The players on the winning team receive a prize of 50 points each.

--Your final score is your remaining points plus any points (50 or 0$)$ you win as a prize.

--You earn 1 cent per point, paid as an Mturk bonus.

\section{Comprehension Questions}

Please answer the following comprehension questions.

1. Suppose all three players on your team spend 30 points each to pull the rope, and all three players on the opposing team spend 20 points each, what will be your Mturk bonus? (Answer: d)
a) 20 cents
b) 30 cents
c) 50 cents
d) 70 cents
e) 80 cents

2. Suppose all three players on your team spend 20 points each to pull the rope, and all three players on the opposing team spend 30 points each, what will be your Mturk bonus? (Answer: $b$ )
a) 20 cents
b) 30 cents
c) 50 cents
d) 70 cents
e) 80 cents

\section{Make Your Decision}

Now it's time to play tug of war. Click Pull to spend your starting points to pull on the rope. Click Ease Up to change your mind and move points back to Your Points.

Your Points: 50

Points spent on pulling: 0 

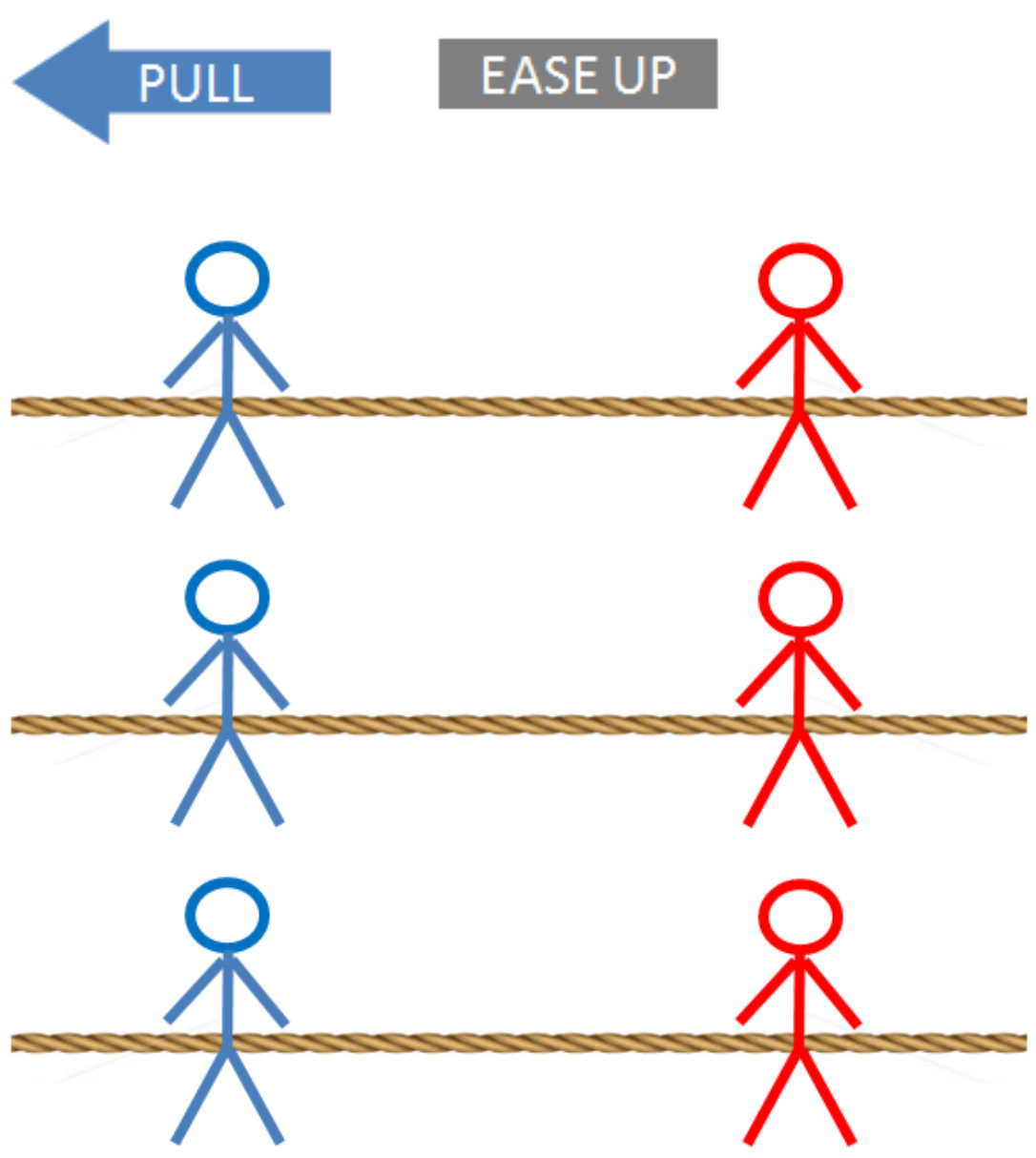

\section{Experiment 2: Political frame}

[Individual competition]

\section{Instructions}

In this HIT, you will play a game of political tug of war with another Mturk participant from the opposite political party. Although the game is fictional, you will earn real money based on the points you score in the game. Specifically, you will earn 1 cent for each point of your final score. After you complete this HIT, you will be matched with another MTurk participant and both of your responses will determine the bonus payments for the game.

You will earn 50 cents for completing this HIT, and you can make additional money in the game. Your additional earnings will be paid to you as a Mturk bonus. All of the game instructions beyond this point refer to money that you can earn above and beyond the 50 cents you automatically earn from completing the HIT.

You said you are a Democrat [Republican]. You will play against another MTurk participant who is a Republican [Democrat] and has completed this same HIT.

[You said your political party is Independent/Other. Would you like to compete on the Republican side, the Democrat side, or stay out of the competition? If you choose to stay out 
of the competition, you will finish the HIT and earn the HIT payment (50 cents), but you will not be able to compete for a prize and will not receive a bonus payment.]

\section{Political Tug of War}

In this game, you play a political tug of war against an opponent from the opposite political party. You pull on one side of a rope and the opponent pulls on the other side. The side that pulls harder wins the competition.

Each player starts with 50 points and decides how many points to spend to pull the rope. Pulling the rope costs you points because it takes a lot of energy. The more points you spend, the harder you pull.

If you pull harder than your opponent by spending more points, then you win the match. If both sides pull with the same amount of force, then it's a tie and the winner is randomly determined by a coin flip.

The winner receives a prize of 50 points and the loser receives 0 points.

Your final score in the game is the points you have left after the competition plus any points you win as a prize. Your final score determines your Mturk bonus payment, 1 cent per point.

Here is an example. You start with 50 points and then spend 20 points to pull the rope. If you spend more points than the opponent, then you win an additional prize of 50 points. Your final score would be your remaining 30 points plus your prize of 50 points for a total of 80 points.

\section{Summary}

--You compete with another participant from the opposite political party in a political tug of war.

--Each player starts with 50 points and decides how many points to spend to pull the rope. You keep the remaining points you don't spend.

--The player who pulls harder wins the match. If there is a tie, the winner is randomly determined.

--The winner receives 50 points.

--Your final score is your remaining points plus any points (50 or 0$)$ you win as a prize.

--You earn 1 cent per point, paid as an Mturk bonus.

\section{Comprehension Questions}

Please answer the following comprehension questions.

1. Suppose you spend 30 points to pull the rope and your opponent spends 20 points, what will be your Mturk bonus? (Answer: d)
f) 20 cents
g) 30 cents
h) 50 cents
i) 70 cents
j) 80 cents

2. Suppose you spend 20 points to pull the rope and your opponent spends 30 points, what will be your Mturk bonus? (Answer: b) 

f) 20 cents
g) 30 cents
h) 50 cents
i) 70 cents
j) 80 cents

\section{Make Your Decision}

Now it's time to play the political tug of war. Click Pull to spend your starting points to pull on the rope toward the Democrat [Republican] side. Click Ease Up to change your mind and move points back to Your Points.

Your Points: 50

Points spent on pulling: 0
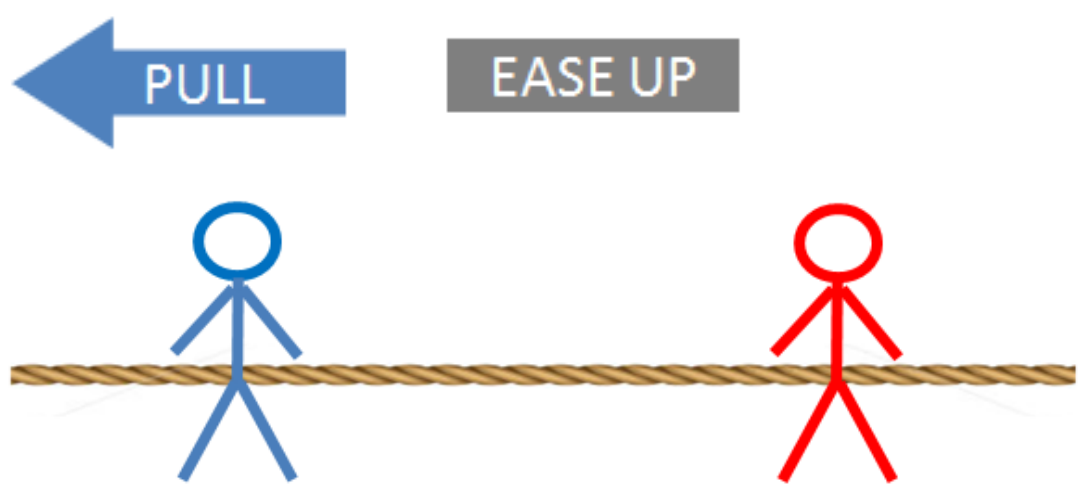

[3-on-3 competition]

\section{Instructions}

In this HIT, you will play a game of political tug of war with other Mturk participants from the opposite political party. Although the game is fictional, you will earn real money based on the points you score in the game. Specifically, you will earn 1 cent for each point of your final score. After you complete this HIT, you will be matched with other MTurk participants and all of your responses will determine the bonus payments for the game.

You will earn 50 cents for completing this HIT, and you can make additional money in the game. Your additional earnings will be paid to you as a Mturk bonus. All of the game instructions beyond this point refer to money that you can earn above and beyond the 50 cents you automatically earn from completing the HIT.

You said you are a Democrat [Republican]. You will play against other MTurk participants who are Republicans [Democrats] and have completed this same HIT.

[You said your political party is Independent/Other. Would you like to compete on the Republican side, the Democrat side, or stay out of the competition? If you choose to stay out of the competition, you will finish the HIT and earn the HIT payment (50 cents), but you will not be able to compete for a prize and will not receive a bonus payment.] 


\section{Political Tug of War}

In this game, you play a political tug of war against an opponent from the opposite political party. You pull on one side of a rope and the opponent pulls on the other side. The side that pulls harder wins the competition.

Each player starts with 50 points and decides how many points to spend to pull the rope. Pulling the rope costs you points because it takes a lot of energy. The more points you spend, the harder you pull.

If you pull harder than your opponent by spending more points, then you win the match. If both sides pull with the same amount of force, then it's a tie and the winner is randomly determined by a coin flip.

You will compete in teams of 3 players. You will be assigned to a team with two other participants from the same political party and your team will compete against another team of 3 participants from the opposite political party. The force of the team's pull is the total points that each player spends to pull the rope. The team that pulls harder wins the competition.

The winning team receives a prize of 50 points for each player and the losing team receives 0 points for each player.

Your final score in the game is the points you have left after the competition plus any points you win as a prize. Your final score determines your Mturk bonus payment, 1 cent per point.

Here is an example. You start with 50 points and then spend 20 points to pull the rope. If your team spends more total points than the opposing team, then you win an additional prize of 50 points. Your final score would be your remaining 30 points plus your prize of 50 points for a total of 80 points.

\section{Summary}

--You compete in a team of three against another team from the opposite political party in a political tug of war.

--Each player starts with 50 points and decides how many points to spend to pull the rope. You keep the remaining points you don't spend.

--The team that pulls harder wins the match. If there is a tie, the winner is randomly determined.

--The players on the winning team receive a prize of 50 points each.

--Your final score is your remaining points plus any points (50 or 0$)$ you win as a prize.

--You earn 1 cent per point, paid as an Mturk bonus.

\section{Comprehension Questions}

Please answer the following comprehension questions.

1. Suppose all three players on your team spend 30 points each to pull the rope, and all three players on the opposing team spend 20 points each, what will be your Mturk bonus? (Answer: d)
f) 20 cents
g) 30 cents
h) 50 cents 

i) 70 cents
j) 80 cents

2. Suppose all three players on your team spend 20 points each to pull the rope, and all three players on the opposing team spend 30 points each, what will be your Mturk bonus? (Answer: b)
f) 20 cents
g) 30 cents
h) 50 cents
i) 70 cents
j) 80 cents

\section{Make Your Decision}

Now it's time to play the political tug of war. Click Pull to spend your starting points to pull on the rope toward the Democrat [Republican] side. Click Ease Up to change your mind and move points back to Your Points.

Your Points: 50

Points spent on pulling: 0

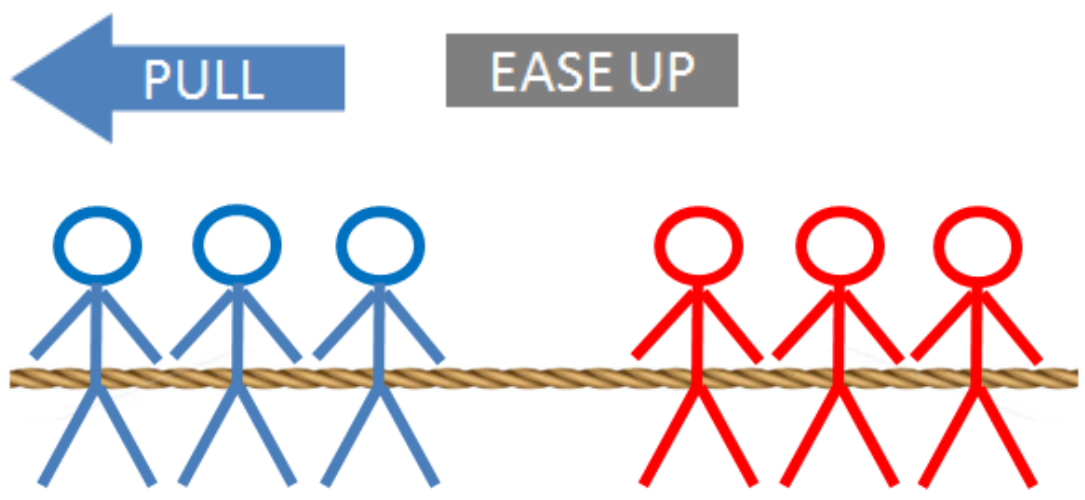

[best-of-3 competition]

\section{Instructions}

In this HIT, you will play a game of political tug of war with other Mturk participants from the opposite political party. Although the game is fictional, you will earn real money based on the points you score in the game. Specifically, you will earn 1 cent for each point of your final score. After you complete this HIT, you will be matched with other MTurk participants and all of your responses will determine the bonus payments for the game.

You will earn 50 cents for completing this HIT, and you can make additional money in the game. Your additional earnings will be paid to you as a Mturk bonus. All of the game instructions beyond this point refer to money that you can earn above and beyond the 50 cents you automatically earn from completing the HIT.

You said you are a Democrat [Republican]. You will play against other MTurk participants who are Republicans [Democrats] and have completed this same HIT.

[You said your political party is Independent/Other. Would you like to compete on the Republican side, the Democrat side, or stay out of the competition? If you choose to stay out 
of the competition, you will finish the HIT and earn the HIT payment (50 cents), but you will not be able to compete for a prize and will not receive a bonus payment.]

\section{Political Tug of War}

In this game, you play a political tug of war against an opponent from the opposite political party. You pull on one side of a rope and the opponent pulls on the other side. The side that pulls harder wins the competition.

Each player starts with 50 points and decides how many points to spend to pull the rope. Pulling the rope costs you points because it takes a lot of energy. The more points you spend, the harder you pull.

If you pull harder than your opponent by spending more points, then you win the match. If both sides pull with the same amount of force, then it's a tie and the winner is randomly determined by a coin flip.

You will compete in teams of 3 players. You will be assigned to a team with two other participants from the same political party and your team will compete against another team of 3 participants from the opposite political party. Then there are three matches in which one player from each team plays tug of war against an opponent from the rival team. The team that wins two out of three matches wins the competition.

The winning team receives a prize of 50 points for each player and the losing team receives 0 points for each player.

Your final score in the game is the points you have left after the competition plus any points you win as a prize. Your final score determines your Mturk bonus payment, 1 cent per point.

Here is an example. You start with 50 points and then spend 20 points to pull the rope. If your team wins two out of three matches, then you win an additional prize of 50 points. Your final score would be your remaining 30 points plus your prize of 50 points for a total of 80 points.

\section{Summary}

--You compete in a team of three against another team from the opposite political party in tug of war. There are three matches between two players.

--Each player starts with 50 points and decides how many points to spend to pull the rope.

You keep the remaining points you don't spend.

--The player who pulls harder wins the match. If there is a tie, the winner is randomly determined.

--The team that wins two out of three matches wins the competition.

--The players on the winning team receive a prize of 50 points each.

--Your final score is your remaining points plus any points (50 or 0 ) you win as a prize.

--You earn 1 cent per point, paid as an Mturk bonus.

\section{Comprehension Questions}

Please answer the following comprehension questions. 
1. Suppose all three players on your team spend 30 points each to pull the rope, and all three players on the opposing team spend 20 points each, what will be your Mturk bonus? (Answer: d)

f) 20 cents

g) 30 cents

h) 50 cents

i) 70 cents

j) 80 cents

2. Suppose all three players on your team spend 20 points each to pull the rope, and all three players on the opposing team spend 30 points each, what will be your Mturk bonus? (Answer: b)

f) 20 cents

g) 30 cents

h) 50 cents

i) 70 cents

j) 80 cents

\section{Make Your Decision}

Now it's time to play the political tug of war. Click Pull to spend your starting points to pull on the rope toward the Democrat [Republican] side. Click Ease Up to change your mind and move points back to Your Points.

Your Points: 50

Points spent on pulling: 0

\section{EASE UP}
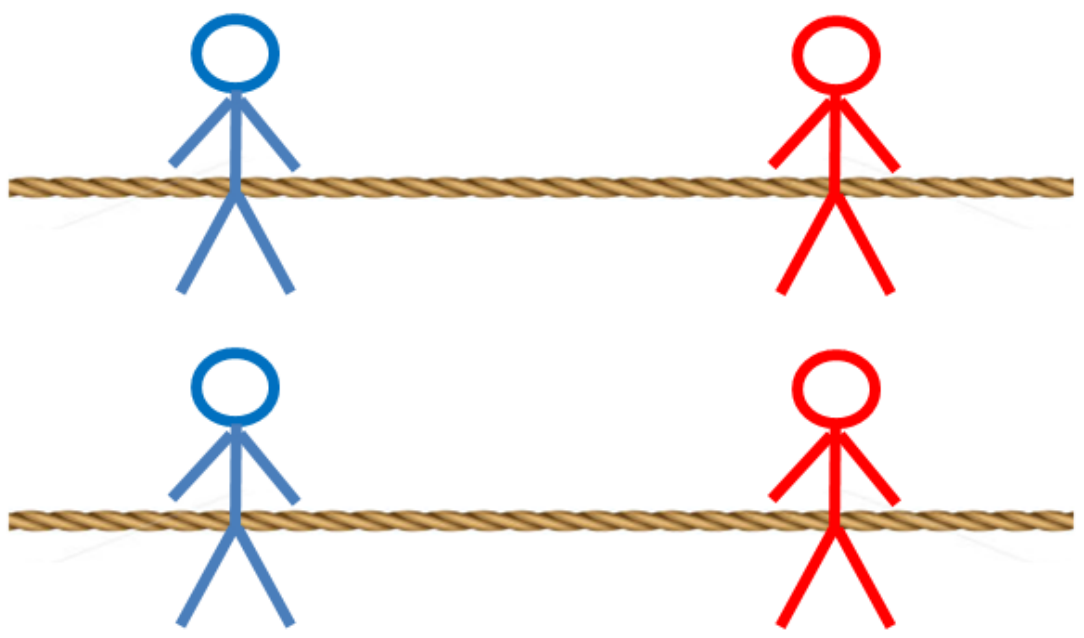


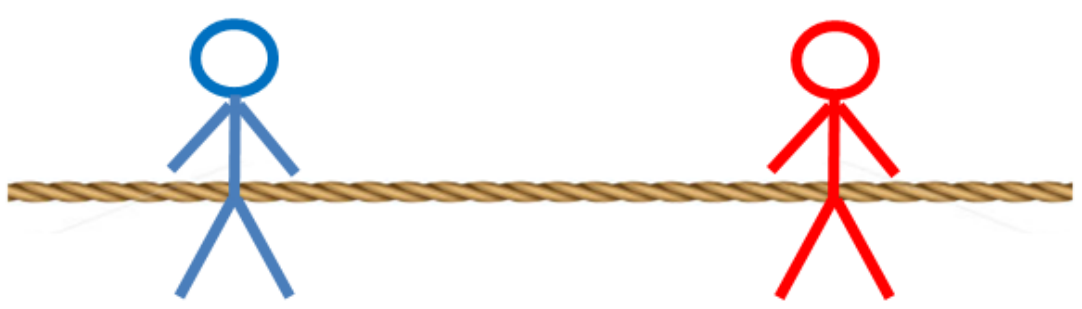

\section{Pre-experiment Demographic Questions}

1. What is your sex?

2. What is your age?

3. What is your race/ethnicity?

4. What political party do you most support? (Democrat/Republican/Independent\&Other)

5. What is your religion?

6. What is your occupation?

7. What is your annual household pre-tax income? (below $\$ 20 \mathrm{k} / \$ 20 \mathrm{k}-\$ 50 \mathrm{k} / \$ 50 \mathrm{k}$ $\$ 80 \mathrm{k} / \$ 80 \mathrm{k}-\$ 100 \mathrm{k} / \$ 100 \mathrm{k}-\$ 200 \mathrm{k} /$ above $\$ 200 \mathrm{k}$ )

\section{Post-experiment Questionnaire}

Generally speaking, which of the following do you consider yourself to be? (If none of these, then please choose the closest option.)

1. Strong Democrat

2. Moderate Democrat

3. Weak Democrat

4. Weak Republican

5. Moderate Republican

6. Strong Republican 